\title{
Toxic anterior segment syndrome in a tertiary Australian healthcare institution
}

Chris HL Lim BSC(Med)(Hons1) MD, ${ }^{1}$ Nathan JY Wong MBBS(Hons), ${ }^{1,2}$ Ching H Ng FRANZCO, ${ }^{1,2}$ Robin A Meusemann FRANZCO, ${ }^{3,4}$ Mark D Daniell MS FRANZCO ${ }^{5}$ and RC Andrew Symons PhD FRANZCO ${ }^{1,6}$

1. Department of Ophthalmology, Royal Melbourne Hospital, Parkville, VIC, Australia

2. Royal Victorian Eye and Ear Hospital, VIC, Australia

3. Ophthalmology Unit, Alfred Hospital, Melbourne, VIC, Australia

4. North West Eye Specialists, Melbourne, Australia

5. Centre For Eye Research Australia, VIC, Australia

6. Department of Surgery, University of Melbourne, VIC, Australia

Correspondence: Associate Professor Andrew Symons, Department of Ophthalmology, Royal Melbourne Hospital, Parkville, VIC 3050, Australia Email: andrew.symons@mh.org.au

Received 13 March 2017; accepted 19 March 2017

Conflict of interest: None

Funding sources: None

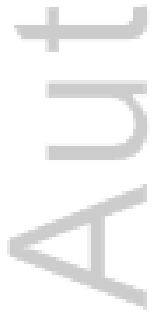

This is the author manuscript accepted for publication and has undergone full peer review but has not been through the copyediting, typesetting, pagination and proofreading process, which may lead to differences between this version and the Version of Record. Please cite this article as doi: $10.1111 /$ ceo.12951

This article is protected by copyright. All rights reserved. 
Toxic anterior segment syndrome (TASS) is an acute sterile inflammatory disorder that follows intraocular exposure to foreign substances. It commonly occurs within 12 to 48 hours after anterior segment surgery. TASS presents in a similar fashion to acute post-operative endophthalmitis, but differs in its time-course and represents a sterile inflammatory response.

Cases were identified in a retrospective audit of patients presenting to our institution for cataract surgery between November 2011 and September 2012. A total of 11 cases of TASS were identified over 12 -months (Table 1 ). This represented $3.6 \%$ of the total number of cases of intraocular surgery performed. Of these, 9 cases occurred within a 4-week period.

The first of the cases occurred in November 2011. Following this, a cluster of seven cases was recognised within a fourteen-day period in May 2012. Intraocular surgery was immediately suspended and a multi-disciplinary investigative committee convened.

Routine cataract surgery was performed in all cases. Patients were followed up in the Ophthalmology clinic on day 1 post-operatively. The following criteria for TASS were used:

o Marked atypical inflammatory response within 48 hours postoperatively

o Significant diffuse corneal oedema

o Anterior chamber inflammation marked by either evidence of fibrin formation or hypopyon

o Minimal vitreous involvement

Upon identification of marked intraocular inflammation, 6 patients underwent vitreous and aqueous biopsies, and received intravitreal injections of vancomycin, 
ceftazidime and dexamethasone. Microbiology testing was performed on all specimens and was negative in all cases. Remaining patients were placed on an initial regimen of intensive topical corticosteroid therapy and reviewed regularly. Patients received regular review.

Preliminary investigations revealed a need to update cleaning and sterilisation workflow processes, and optimise inventory management of sterile stock supplies and medications. Steps were taken to address these issues.

Instruments had been cleaned on a prolonged sterilisation cycle, which can result in a breakdown of electroplated metal coatings. Consequent exposure of the intracameral environment to metal ions may precipitate a toxic response. ${ }^{1}$ Reusable ophthalmic instruments were henceforth cleaned and sterilised separately on a shorter cycle

Use of reusable cannulas was not compliant with American Society of Cataract and Refractive Surgery (ASCRS) recommendations and all intraocular cannulas were replaced with disposable single-use equivalents. ${ }^{2} 3$

Medications and Ophthalmic Viscosurgical Devices (OVD) used within the perioperative period have also been identified as precipitants by other investigators. The use of intracameral agents has been reported to be associated with the generation of free radicals, which may contribute to TASS. Most commonly, contaminants such as endotoxins or other impurities have been identified as triggers. ${ }^{2}$ None of these factors were identified as likely causes. Interestingly, the use of OVD materials may protect against endothelial damage in this instance by acting as scavengers of free radicals that may have been produced by intracameral agents or through phacoemulsification. ${ }^{4}$ 
A search for airborne and waterborne environmental microbial or lipopolysaccharide contamination did not find any significant sources of risk.

All patients were followed, and reported a reduction in symptoms. Final visual outcomes were favourable in all cases (Table 2). Symptoms, inflammation and corneal oedema resolved within six months in all cases. In one case, complete symptomatic and clinical resolution occurred within one week. No cases of secondary glaucoma occurred.

Surgery was recommenced after root cause analysis was completed, initially with a reduced caseload. However, two further cases of TASS were encountered and intraocular surgery was re-suspended. Another in-depth case review, led by our Quality Improvement team, did not identify any further precipitants. Following these investigations, a further case of TASS was identified three months following this third cluster. No further cases were identified between September 2013 and February 2017, despite more than 1000 cataract surgeries having been performed in this time.

TASS typically occurs in an outbreak fashion, with a large recent retrospective case series reporting an incidence of $0.22 \% .{ }^{2}$ Incidence rates of up to $38 \%$ have been reported during the outbreak period. ${ }^{5}$ I nvestigations into the likely cause of TASS can be fraught with challenges given the diverse range of possible precipitants. This has been extensively investigated by the ASCRS Task Force, which has provided an analysis of the most commonly reported risk factors for TASS. ${ }^{3}$

A thorough multidisciplinary approach in the investigation of potential causes of TASS is often warranted. More commonly, as reflected by our experience, a definite 
aetiology cannot be identified, despite review of all perioperative possibilities. Similar experiences have been reported regarding difficulties in establishing a definite precipitant for these clusters of cases. ${ }^{6}$ It is important for clinicians to consider acute postoperative endophthalmitis in the differential diagnosis of TASS, since endophthalmitis, which requires prompt treatment to minimise the risk of visual loss, may present with features typically associated with TASS. ${ }^{7}$ 


\section{Acknowledgements:}

The authors wish to thank the following employees of Melbourne Health who contributed their expertise to the root cause analysis of the TASS cluster: Chris Taylor, Dr Daniel Chiu, Grace J ury, Hannele Parojarvi, Janice Stielow, Lisa Li, Louise Hobbs, Mary Wong, Melanie Yensch, Dr Peter Bradford, Dr Robin Meusemann, Dr Robin Riley, A/Prof Rodney J udson, Sally Henderson, Susan Garbutt, Tania Kent, Verna Ramsay, Dr Vincent Sinickas

We wish to thank Dr Cate Kelly and A/Prof Kate Drummond for their critical reading of the manuscript. 


\section{REFERENCES}

1. Smith CA, Khoury J M, Shields SM, Roper GJ , Duffy RE, Edelhauser HF, Lubniewski Al. Unexpected corneal endothelial cell decompensation after intraocular surgery with instruments sterilized by plasma gas. Ophthalmology 2000; 107: 1561-6.

2. Bodnar Z, Clouser S, Mamalis N. Toxic anterior segment syndrome: Update on the most common causes. Journal of Cataract \& Refractive Surgery 2012; 38: 1902-10.

3. Hellinger W, Bacalis L, Edelhauser H, Mamalis N, Milstein B, Masket S. ASCRS Ad Hoc Task Force on Cleaning and Sterilization of Intraocular I nstruments. Recommended practices for cleaning and sterilizing intraocular surgical instruments. J Cataract Refract Surg 2007; 33: 1095-100.

4. Takahashi H, Suzuki H, Shiwa T, Sakamoto A. Alteration of free radical development by ophthalmic viscosurgical devices in phacoemulsification. Journal of Cataract \& Refractive Surgery 2006; 32: 1545-8.

5. Hellinger WC, Hasan SA, Bacalis LP, Thornblom DM, Beckmann SC, Blackmore C, Forster TS, Tirey JF, Ross MJ, Nilson CD. Outbreak of toxic anterior segment syndrome following cataract surgery associated with impurities in autoclave steam moisture. Infection Control 2006; 27: 294-8.

6. Moyle W, Yee RD, Burns JK, Biggins T. Two consecutive clusters of toxic anterior segment syndrome. Optometry \& Vision Science 2013; 90: e11-e23.

7. Rishi E, Rishi P, Sengupta S, Jambulingam M, Madhavan HN, Gopal L, Therese $\mathrm{KL}$. Acute postoperative Bacillus cereus endophthalmitis mimicking toxic anterior segment syndrome. Ophthalmology 2013; 120: 181-5. 


\section{TABLES}

Table 1: Demographic characteristics

\begin{tabular}{llllllll}
\hline Cluster & Patient & Age & Sex & DM/ HTN & Operated Eye & POHx & Operation \\
\hline $\mathbf{1}$ & 1 & 50 & M & HTN & Right & Blunt injury OD & PKE/PClOL \\
\hline $\mathbf{2}$ & 2 & 65 & F & NA & Left & Nil significant & PKE/PClOL \\
\hline $\mathbf{2}$ & 3 & 72 & F & DM & Right & Nil significant & PKE/PCl OL \\
\hline $\mathbf{2}$ & 4 & 78 & F & HTN & Right & Glaucoma, blepharitis & PKE/PCl OL \\
\hline $\mathbf{2}$ & 5 & 75 & F & HTN & Left & Fuchs endothelial dystrophy & PKE/PCl OL \\
\hline $\mathbf{2}$ & 6 & 70 & F & NA & Left & Pseudoexfoliation syndrome & PKE/PClOL \\
\hline $\mathbf{2}$ & 7 & 74 & F & DM & Right & Nil significant & PKE/PClOL/IVTA \\
\hline $\mathbf{2}$ & 8 & 61 & M & NA & Left & Right amblyopia & PKE//PClOL \\
\hline $\mathbf{3}$ & 9 & 70 & M & DM & Right & Nil significant & PKE/PCl OL \\
\hline $\mathbf{3}$ & 10 & 76 & F & NA & Left & Blepharitis & PKE/PClOL
\end{tabular}


Table 2: Clinical progress

Patient

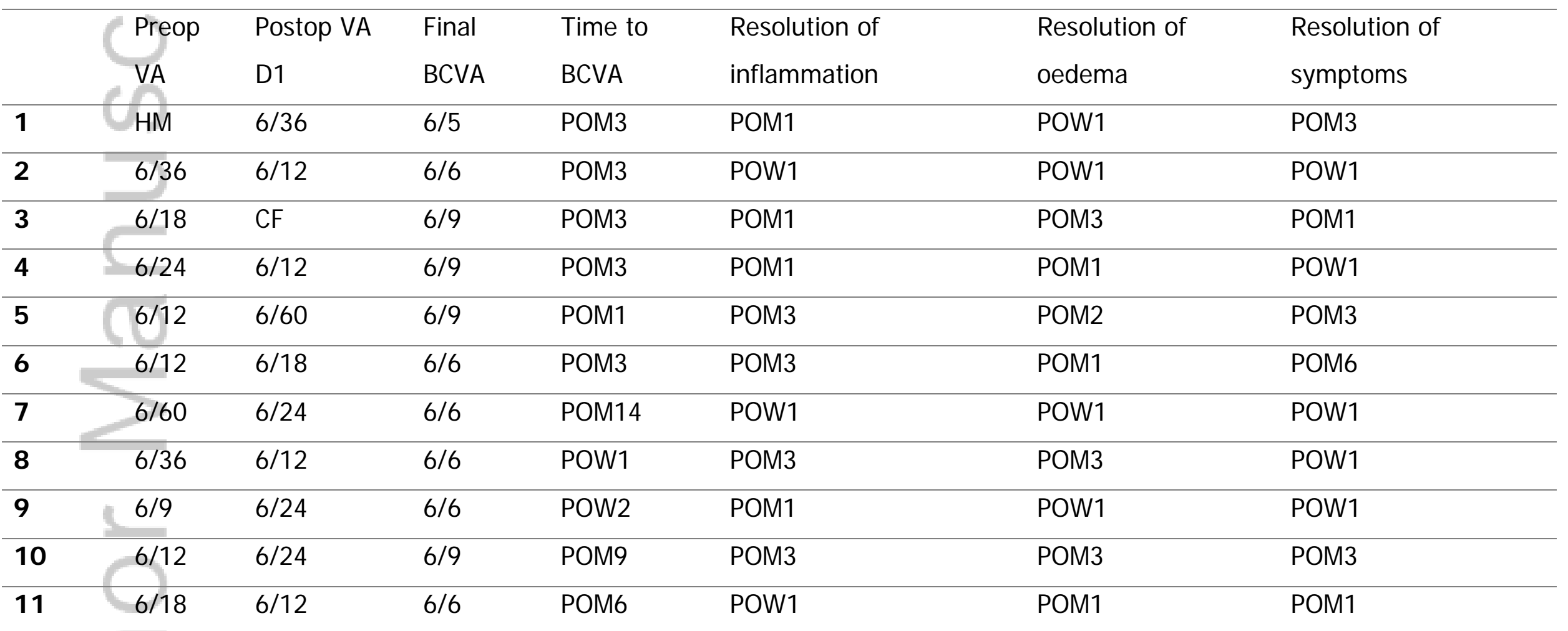

\section{Clinical signs and symptoms}

\section{Vision}

PI


POM, postoperative month, POW, postoperative week

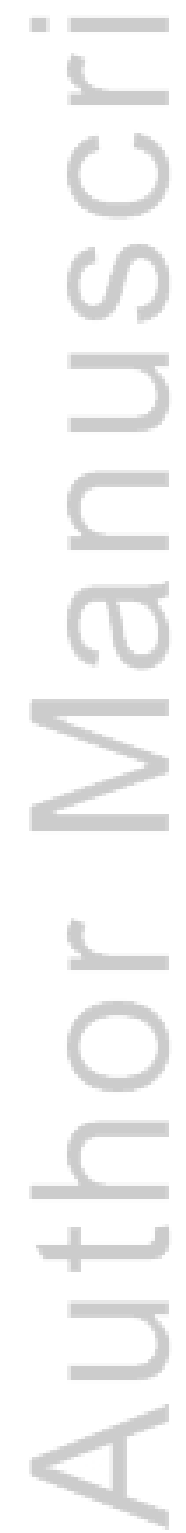

This article is protected by copyright. All rights reserved. 


\section{University Library}

\section{- M M N E R VA A gateway to Melbourne's research publications}

Minerva Access is the Institutional Repository of The University of Melbourne

Author/s:

Lim, CHL;Wong, NJY;Ng, CH;Meusemann, RA;Daniell, MD;Symons, RCA

Title:

Toxic anterior segment syndrome in a tertiary Australian healthcare institution

Date:

2017-09-01

Citation:

Lim, C. H. L., Wong, N. J. Y., Ng, C. H., Meusemann, R. A., Daniell, M. D. \& Symons, R. C. A. (2017). Toxic anterior segment syndrome in a tertiary Australian healthcare institution. CLINICAL AND EXPERIMENTAL OPHTHALMOLOGY, 45 (7), pp.750-752. https:// doi.org/10.1111/ceo.12951.

Persistent Link:

http://hdl.handle.net/11343/292884 